\title{
Spatial distribution and sources of organochlorine pesticides in surface waters of Shanghai, China
}

\author{
Chong Chen ${ }^{1} \cdot$ Tongtong $\mathrm{Li}^{1} \cdot$ Wenbing Zou ${ }^{2} \cdot$ Songsong Chen ${ }^{1} \cdot$ Kai Zhang ${ }^{1} \cdot$ Limin Ma $^{1}$ (D)
}

Received: 3 March 2020 / Accepted: 14 September 2020 / Published online: 26 September 2020

(c) Springer Nature Switzerland AG 2020

\begin{abstract}
The concentrations, distribution, influencing factors, and sources of 26 organochlorine pesticides (OCPs) were investigated in surface waters of Shanghai. Surface waters in this study refer to the freshwater that contains particles smaller than $0.45 \mu \mathrm{m}$ in size. Total concentrations of OCPs ranged from 5.90 to $158.16 \mathrm{ng} / \mathrm{L}$ with a mean value of $78.11 \mathrm{ng} / \mathrm{L}$. The OCP concentrations were generally low, but with a few relatively high concentrations at sites in the northern and southern regions of Shanghai. Dissolved oxygen, electrical conductivity, $\mathrm{pH}$ and oxidation-reduction potential had an important impact on the distribution of OCPs, which showed a significant negative correlation $(p<0.01)$. Source apportionment was carried out using isomer ratios of OCPs and Absolute Principal Component Scores-Multiple Linear Regression. Six principal components of OCPs were identified, and the contribution rates and contribution amounts were ranked: Heptachlor epoxide $>\mathrm{HCH} s>$ Endosufan and Methoxychlor $>$ Propachlor $>$ Heptachlor and DDTs $>$ Dacthal and Chlordane. The contribution of historic residual $\mathrm{HCH}$ in Shanghai's surface waters was not significantly different from that of atmospheric deposition, and a part of $\mathrm{HCB}$ was likely from the degradation of HCHs. DDTs were mainly from historical residues, although some were derived from recent inputs, and the main sources of heptachlors were also the historical residues. However, the recent input and historical residues of aldrins were both noticeable. The fluctuation of OCPs pollution levels and source differences among different intensive land-use types were relatively insignificant $(p>0.05)$.
\end{abstract}

Keywords Influencing factor · Dichlorodiphenyl trichloroethane $\cdot$ Benzene hexachloride $\cdot$ Principal component $\cdot$ Landuse types

\section{Introduction}

Organochlorine pesticides (OCPs) are a class of persistent organic pollutants (POPs) that exist widely in the environment with high residues and strong bioconcentration [1]. Their chemical properties are very stable, with persistence, liposolubility, toxicity, and bioaccumulation [2]. The use of pesticides in agricultural production has become a common practice to prevent or reduce losses caused by infectious plant diseases and to improve crop yield and quality [3]. However, most of the applied pesticides escape to the environment through surface runoff, spraying residues, infiltration into or as residues on crops, and can migrate over long distances [4]. OCPs can migrate into a watershed through atmospheric transport, wet and dry deposition, water flow transport,

Electronic supplementary material The online version of this article (https://doi.org/10.1007/s42452-020-03507-2) contains supplementary material, which is available to authorized users.

$\triangle$ Limin Ma, Imma@tongji.edu.cn| 'State Key Laboratory of Pollution Control and Resources Reuse, College of Environmental Science and Engineering, Tongji University, 1239 Siping Road, Shanghai 200092, People's Republic of China. ${ }^{2}$ Shanghai Key Laboratory of Special Artificial Microstructure Materials and Technology, School of Physics Science and Engineering, Tongji University, Shanghai 200092, People's Republic of China. 
and environmental medium exchange etc., and poses a threat to aquatic ecosystems [2]. In order to eliminate POPs, the Stockholm Convention on Persistent Organic Pollutants was signed in 2001 in Stockholm, Sweden [5]. By 2011, the number of controlled pollutants in the convention had increased to twenty-two, of which OCPs accounted for thirteen [5].

Surface water resources are abundant in China, and have received increasing amounts of industrial, agricultural and domestic sewage with population growth and rapid economic development in recent decades, which have caused serious pollution [6]. As a result, surface water pollution has become an important social problem related to public safety and human health, among which POPs pose the greatest threat to human beings and ecosystems. Previous studies have shown that some important rivers in China (e.g., Shaying River, Yellow River, and Pearl River) have been polluted by OCPs to varying degrees [7-9]. OCPs in urban surface waters can potentially cause persistent damage to ecosystems and human health.

Numerous studies have focused on the distribution characteristics, sources and ecological risk assessment of OCPs in river systems, and most research has concentrated on individual rivers [7], whereas the study of surface waters in urban river networks is very limited. However, in the plain regions of southern China, several rivers are intertwined to form river networks. Surface water is distributed throughout cities, and the characteristics of OCPs in surface waters may be easily affected by the surrounding environment and different intensive land-use types [10]. Therefore, the investigation of OCPs in the surface waters of urban river networks is of great significance for analyzing their environmental behavior and for understanding the migration and transformation of OCPs in rivers. However, currently, few relevant studies have been reported [11].

Shanghai is a city located in the plains of southern China and has a typical river network [12]. Its industrialization and urbanization are well-developed and its population density is high [13]. Shanghai's surface waters can be affected by many factors, including industry, agriculture, and the life of residents [6]. The purpose of this study is to (1) explore the concentrations and spatial variation of OCPs in surface waters of Shanghai, (2) analyze the correlation between physical and chemical factors and OCPs distribution, (3) identify the sources and principal components of OCPs, (4) quantitatively assess the contribution rate and contribution amount of each principal component. The results will be helpful for understanding the environmental behavior and fate of OCPs in the surface waters of developed cities globally.

\section{Materials and methods}

\subsection{Study area and sample collection}

The study area is located in Shanghai $\left(30^{\circ} 40^{\prime}-31^{\circ}\right.$ $53^{\prime}, 120^{\circ} 52^{\prime}-122^{\circ} 12^{\prime}$ ), which is an important international metropolis in China with functions of industry, agriculture, residence, and commerce, and covers an area of $6340.5 \mathrm{~km}^{2}$ [12]. Shanghai is located on the alluvial plain of the Yangtze River Delta, at an average altitude of $4 \mathrm{~m}$ above sea level [12]. There are approximately 33,127 rivers or creeks in Shanghai, with a total length of $\sim 24,915 \mathrm{~km}$ and a total water surface area of $\sim 642.7 \mathrm{~km}^{2}$ [10]. These rivers are interconnected with each other, thus producing a river network.

According to a grid method, 53 sampling sites were set up and divided into five types of intensive land-use (Fig. 1). Detailed information on the sampling areas is described in Table A.1, and the typical characteristics of different intensive land-use types are shown in Fig. A.1. Surface water samples were collected from December 2018 to February 2019. Samples were collected from the middle of the rivers at a depth of $5-15 \mathrm{~cm}$ using a plexiglass sampler (three duplicates) and stored in $1 \mathrm{~L}$ brown glass bottles. The collected surface water samples were immediately transported to the laboratory, stored at $4{ }^{\circ} \mathrm{C}$ with preservatives $(0.10 \mathrm{~g} / \mathrm{L}$ ascorbic acid, $0.35 \mathrm{~g} / \mathrm{L}$ ethylenediaminetetraacetic acid disodium salt, and $9.4 \mathrm{~g} / \mathrm{L}$ potassium dihydrogen citrate) before being analyzed within $24 \mathrm{~h}$. A Global Positioning System (GPS) device was used to locate sample sites. The temperature, dissolved oxygen (DO), electrical conductivity (EC), $\mathrm{pH}$, and oxygen reduction potential (ORP) were measured in situ at each sampling site using a portable water quality monitor (YSI proplus, USA).

\subsection{Sample preparation and analysis}

Surface water samples were filtered using $0.45 \mu \mathrm{m}$ pore size glass fiber filters (ANPEL, China), which were calcined for $4 \mathrm{~h}$ at $400{ }^{\circ} \mathrm{C}$ and then weighed before use. The filtered water samples were extracted by solid phase extraction (ANPEL CG1824, China). Before the extraction, $6 \mathrm{~mL}$ cartridges packed with $500 \mathrm{mg}$ of $\mathrm{C} 18$ (ANPEL, China) were activated by adding $5 \mathrm{~mL}$ ethyl acetate, $10 \mathrm{~mL}$ methanol, and $10 \mathrm{~mL}$ ultra-pure water in turn. Filtered water samples were then passed through the cartridges at a flow rate of $10 \mathrm{~mL} / \mathrm{min}$, and the cartridges were eluted using $5 \mathrm{~mL}$ methanol and $5 \mathrm{~mL}$ dichloromethane after extraction. The elution was dried with anhydrous sodium sulfate, and then transferred with 
Fig. 1 Location of sampling points in the surface waters of Shanghai under different intensive land-uses

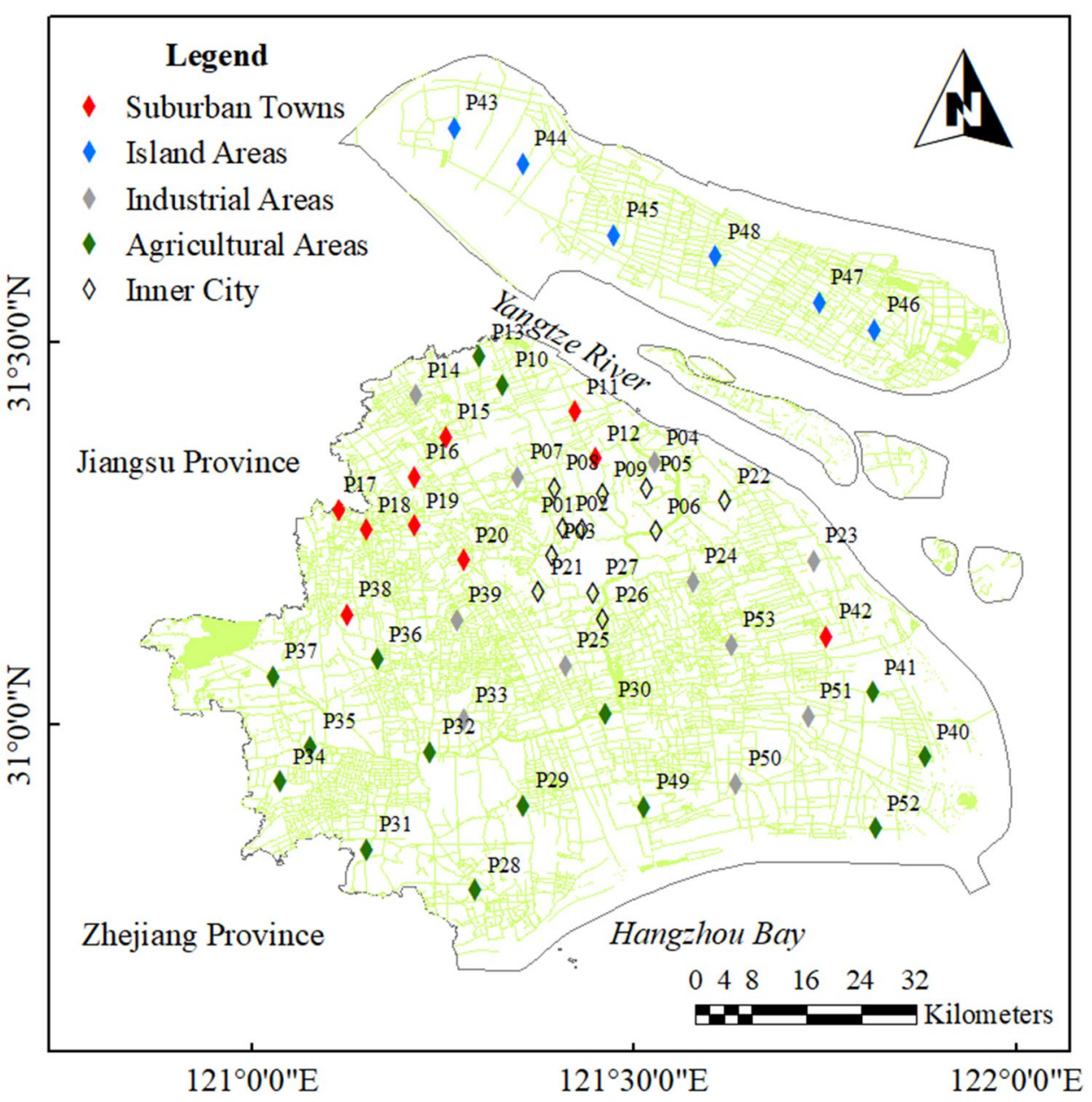

dichloromethane and concentrated to $0.7 \mathrm{~mL}$ by an antiseptic 24-bit nitrogen blower (ANPEL DC24-Rt, China). Finally, the concentrated samples were fixed to $1 \mathrm{~mL}$ after the addition of $\sim 0.3 \mathrm{~mL}$ methanol. The filtered glass fiber membranes were dried naturally and then weighed again. The total suspended solids (TSS) content of the surface water samples could be calculated according to the added weight.

The OCPs concentrations in surface water samples were measured using Gas-Chromatography-Mass Spectrophotometry (GC-MS, Thermo Fisher Trace DSQII-MS, USA) in El mode equipped with a HP-5MS capillary column (30.0 $\mathrm{m} \times 0.25 \mathrm{~mm} \times 0.25 \mu \mathrm{m}$ ) with helium as a carrier gas at a flow rate of $1.2 \mathrm{~mL} / \mathrm{min}$. The oven temperature was held at $70^{\circ} \mathrm{C}$ for $1.5 \mathrm{~min}$ before being increased to $200^{\circ} \mathrm{C}$ at a rate of $10^{\circ} \mathrm{C} / \mathrm{min}$, and was then continually increased by $7^{\circ} \mathrm{C} / \mathrm{min}$ until $320^{\circ} \mathrm{C}$, which was held for $3 \mathrm{~min}$. The injector was set at $275^{\circ} \mathrm{C}$. The following $26 \mathrm{OCPs}$ were analyzed: Etridiazole, Chloroneb, Propachlor, $\mathrm{a}-\mathrm{HCH}, \beta-\mathrm{HCH}$, $\gamma-\mathrm{HCH}, \delta-\mathrm{HCH}, \mathrm{HCB}$, Chlorothalonil, Heptachlor, Aldrin, Dacthal (DCPA), Heptachlor epoxide, trans-chlordane, cis-chlordane, Endosufan I, Endosufan II, trans-nonachlor, $\mathrm{p}, \mathrm{p}^{\prime}-\mathrm{DDE}, \mathrm{p}, \mathrm{p}^{\prime}-\mathrm{DDD}, \mathrm{p}, \mathrm{p}^{\prime}-\mathrm{DDT}$, Dieldrin, Endrin, Chlorobenzilate, Endosufan sulfate, and Methoxychlor. The standard solutions of these OCPs were purchased from Sigma (USA). All solvents used for sample processing (e.g., ethyl acetate, methanol, and dichloromethane) were HPLC grade and obtained from ANPEL (China).

\subsection{Quality assurance and quality control}

The concentrations of OCPs in this study were quantified using the United States Environmental Protection Agency's (USEPA) internal standard method [14]. The internal standards are pure compounds added to an extract or standard solution in a known amount and used to measure the relative responses of the method analytes [14]. In this study, deuterated polycyclic aromatic hydrocarbons (PAHs) of $100 \mathrm{ng} / \mu \mathrm{L}\left(\mathrm{d}_{10}\right.$-acenaphthene, $\mathrm{d}_{10}$-phenanththrene, $\mathrm{d}_{12}$-chrysene) (Sigma, USA) were used as the internal standard solution according to the USEPA method [14]. In addition, procedural blanks and field blanks were performed to check for interference and cross-contamination. Blank samples and standard samples were tested every 
ten samples. The linearity coefficients $\left(\mathrm{R}^{2}\right)$ of the standard curve ranged from 0.9906 to 0.9993 . Target compounds were under the limit of detection in blank samples. The recoveries of deuterated PAHs were between 62.5 and $126.3 \%$ in surface water samples. The limits of detection (LOD) were $0.24-1.83 \mathrm{ng} / \mathrm{L}$ with a signal-to-noise ratio $(\mathrm{S} / \mathrm{N})$ of 3 , and the limits of quantification (LOQ) were $0.80-6.14 \mathrm{ng} / \mathrm{L}$ with a $\mathrm{S} / \mathrm{N}$ of 10 . All of the analytical results that were lower than the LOQ were reported as half of the LOQ, while those lower than the LOD were reported as not detected, with zero being assigned for statistical purposes.

\subsection{Data analysis}

To identify the principal components of OCPs and their contribution rates and contribution amounts in surface waters of Shanghai, the Absolute Principal Component Scores-Multiple Linear Regression (APCS-MLR) model was adopted [15]. The equations and the process described by Chen et al. [16] were applied in the present study.

The data were statistically analyzed using IBM SPSS Statistics version 25 (IBM, USA). A variance analysis $(p<0.05)$ of total OCPs among different intensive land-use types was conducted by a one-way ANOVA test. The correlation analysis was performed using a Pearson correlation, and the level of significance was set at $p<0.05$ (two tailed).

The spatial distribution maps of OCPs in Shanghai's surface waters were drawn by the interpolation method in ArcGIS version 10.2 (ESRI, USA). The inverse distance weight (IDW) method was used in the interpolation model.

Redundancy analysis (RDA) is a direct gradient analysis method, which can evaluate the correlation between multiple sets of species data and multiple sets of environmental data from a statistical point of view, and analyze the causes of variation of species data [17]. RDA has been widely used in the field of ecology. RDA was performed in this study using Canoco version 5.0 (Microcomputer Power, USA). The significance analysis of the ranked results was performed by an unrestricted permutation test, and the number of inspections was set to 499 .

\section{Results and discussion}

\subsection{Occurrence of OCPs in surface water}

The concentrations of OCPs in surface waters of Shanghai ranged from 5.90 to $158.16 \mathrm{ng} / \mathrm{L}$ with a mean value of $78.11 \mathrm{ng} / \mathrm{L}$ (Table A.2) [18]. Table A.3 has specified the detailed information of OCP compounds analyzed in different studies. The concentrations in Shanghai were higher than those from other areas, for example, 12.3-77.5 ng/L in the Shaying River of China, $0.67-4.90 \mathrm{ng} / \mathrm{L}$ in the Yellow
River, China, 0.009-5.530 ng/L in the Tiber River, Italy, 0.44-3.52 ng/L in the Sarno River, Italy, and ND-51.1 ng/L in the Moscow River, Russia. Our findings were similar to the concentrations of 9.7-122.5 $\mathrm{ng} / \mathrm{L}$ reported for the Pearl River, China, and slightly lower than those from rivers elsewhere in China, e.g., 14.78-180.6 ng/L in the Daling River, China, 3.18-171.28 ng/L in the Hunhe River, China, and $<0.08-197.71 \mathrm{ng} / \mathrm{L}$ in the Yongding River Basin, China (Table A.3). Furthermore, our findings were much lower than reports of concentration ranging from 2 to $1200 \mathrm{ng} / \mathrm{L}$ in rivers in other Asian countries (e.g., the Brahmaputra River and the Hooghly River, India, and the Chenab River, Pakistan, and also much lower than the reported range in concentration of 3-5410 ng/L for river water in Korea, and 52-285 ng/L in the Indus River, Pakistan (Table A.3). Overall, the concentrations of OCPs in the surface waters of Shanghai were therefore basically the same as those reported in other parts of China, lower than those in other Asian developing countries, but higher than those in Italy, Russia, and other European countries (Table A.3).

Figure 2 shows the concentrations of 26 OCPs in surface waters of Shanghai. For the individual compounds, Chloroneb, Chlorobenzilate, and Chlorothalonil were the major pollutants, with concentrations of $13.08 \pm 5.95 \mathrm{ng} / \mathrm{L}, 7.56 \pm 3.25 \mathrm{ng} / \mathrm{L}$, and $5.95 \pm 2.29 \mathrm{ng} / \mathrm{L}$, respectively (Fig. 2). On the other hand, trans-nonachlor $(0.66 \pm 0.35 \mathrm{ng} / \mathrm{L})$, cis-chlordane $(0.66 \pm 0.49 \mathrm{ng} / \mathrm{L})$, and $\mathrm{p}, \mathrm{p}^{\prime}-\mathrm{DDD}(0.77 \pm 0.63 \mathrm{ng} / \mathrm{L})$ were the three individual compounds with the lowest concentrations (Fig. 2). The average concentrations of the other 20 OCPs ranged from 1.01 to $4.45 \mathrm{ng} / \mathrm{L}$ (Fig. 2). Chlorobenzilate, Chlorothalonil, and $\mathrm{p}, \mathrm{p}^{\prime}$-DDE had the highest detection frequencies $(92.5 \%$, $90.6 \%$, and $90.6 \%$, respectively), while p, $p^{\prime}-D D D$, cischlordane, Endosufan I, and Endosufan II had the lowest detection frequencies $(32.1 \%, 41.5 \%, 54.7 \%$, and $54.7 \%$, respectively), and the other 20 OCPs detection frequencies ranged from 58.5 to $84.9 \%$ (Fig. 2). China's Environmental Quality Standards for Surface Water (GB 3838-2002) and the National Recommended Water Quality Criteria of the USEPA were adopted to evaluate the surface water quality in Shanghai (Table A.2) [18]. These metrics provide useful assistance in efforts to protect the aquatic environment. The results showed that concentrations of OCP residues were far below the standard limits set by both China and the United States, indicating that OCP concentrations in the surface waters of Shanghai were safe for aquatic organisms (Table A.2).

\subsection{Spatial variations of OCPs in surface waters}

In general, the concentration of OCPs was well-distributed in the surface waters of Shanghai. The highest levels of OCPs were in the southern (P49, $158.16 \mathrm{ng} / \mathrm{L})$ and northern 


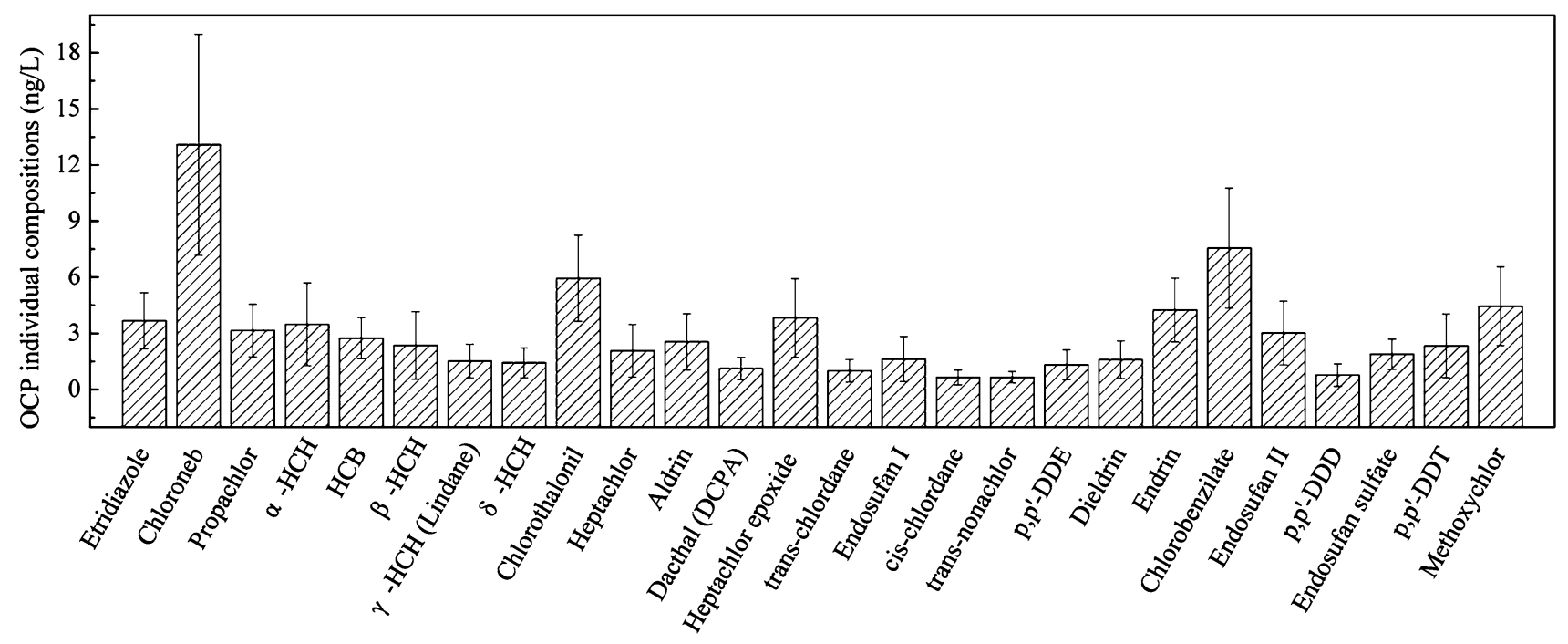

Fig. 2 Concentration statistics of 26 OCP individuals in surface waters of Shanghai
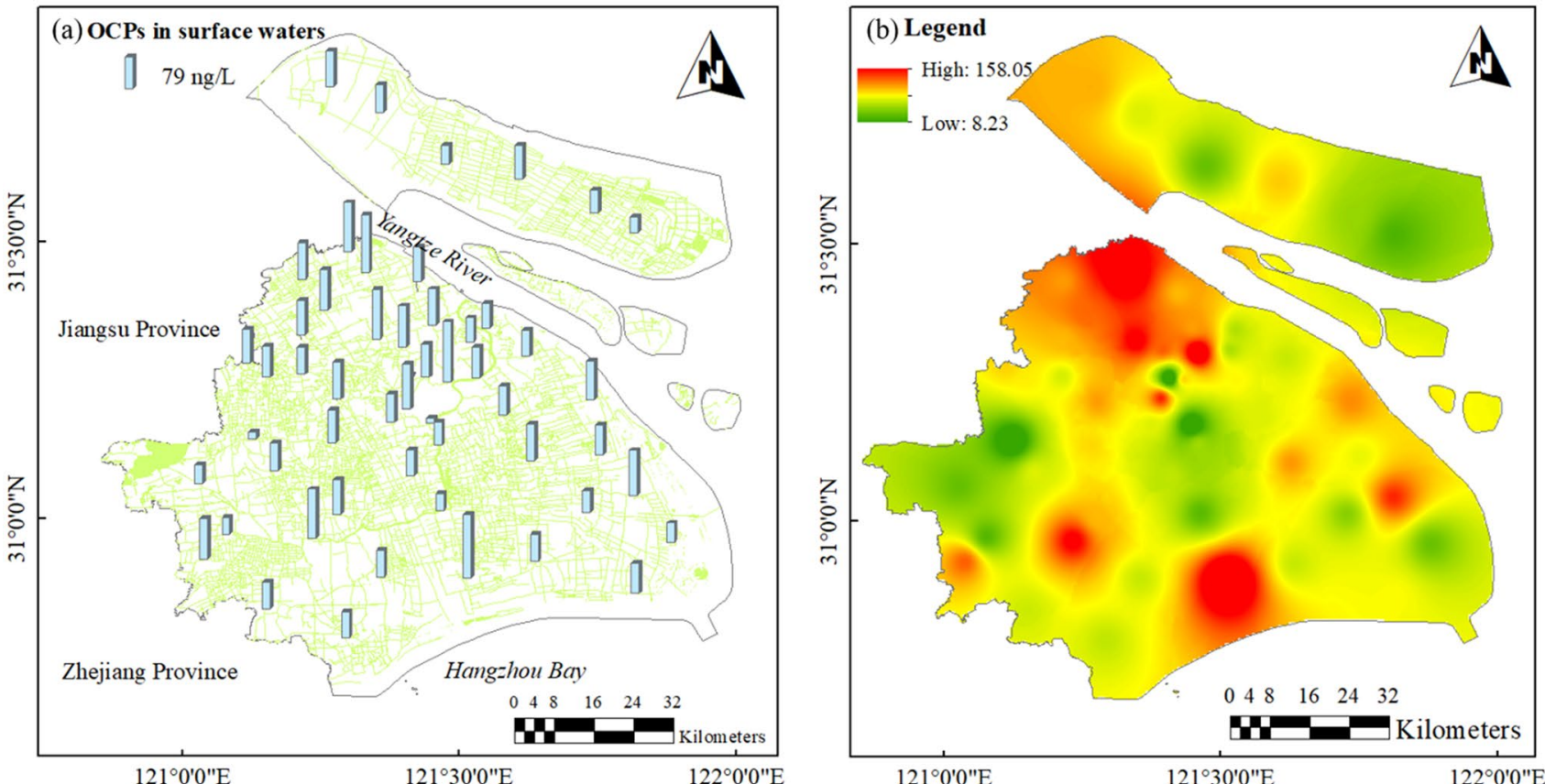

Fig. 3 Spatial distribution characteristics of OCPs in surface waters of Shanghai

regions (P10, $143.81 \mathrm{ng} / \mathrm{L})$, which are both agricultural areas (Fig. 3). Another high concentration area was in the northern side of the inner city (S9, $150.99 \mathrm{ng} / \mathrm{L}$ ) (Fig. 3). According to Fig. 3 , the areas with high OCP concentrations were also areas where agricultural cultivation was concentrated. In order to ensure high crop yields, farmers usually use high inputs of fertilizers and pesticides. The lowest concentration of OCPs occurred in the southern side of the inner city $(\mathrm{P} 2,5.90 \mathrm{ng} / \mathrm{L} ; \mathrm{P} 27,12.47 \mathrm{ng} / \mathrm{L})$ and in the western suburban towns of Shanghai (P38, $16.45 \mathrm{ng} / \mathrm{L})$ (Fig. 3). There was little agricultural activity in these areas, and the water flow rates were relatively high, resulting in fast diffusion and dilution of OCPs. Overall, the OCP concentrations in the surface waters of Shanghai were generally low, with a few relatively high concentration sites in the northern and southern regions.

The OCP concentration difference among five intensive land-use types was relatively insignificant $(p>0.05)$, 
and the ranking was as follows: agricultural areas $(85.58 \pm 38.35 \mathrm{ng} / \mathrm{L})>$ industrial areas $(80.94 \pm 20.16 \mathrm{ng} / \mathrm{L})>$ suburban towns $(77.70 \pm 23.52 \mathrm{ng} / \mathrm{L})>$ inner city $(72.96 \pm 41.53 \mathrm{ng} / \mathrm{L})>$ island areas $(64.40 \pm 19.93 \mathrm{ng} / \mathrm{L})$ (Fig. A.2). It is worth noting that the concentration of OCPs in the inner city varied the most with the maximum standard deviation (S.D.) of $41.53 \mathrm{ng} / \mathrm{L}$ among all the areas (Fig. A.2), which was related to frequent human activities. Some rivers in the inner city have experienced artificial ecological floating islands, regular aeration, sediment dredging, and other water protection measures, which can be beneficial for improving water quality and accelerating the degradation of organic pollutants. However, some other rivers had coastal agricultural cultivation in the past, which was discovered during sampling, and the application of fertilizers and pesticides could make them continuously released from soil or sediment to surface waters over a long period of time [19]. Therefore, for urban rivers, it is crucial to strengthen management.

\subsection{Factors influencing the spatial variations of OCPs}

The behavior and fate of OCPs in the environment are closely related to their own physicochemical properties, and also closely related to various physical and chemical factors in their environment [20]. The OCP concentrations in the surface waters of Shanghai showed a significant negative correlation with DO (Fig. 4a), EC (Fig. 4b), pH (Fig. 4c), and ORP (Fig. 4d) ( $p<0.01)$. DO is an important indicator for reflecting water quality, and many organic pollutants are decomposed by aerobic microbial activity when discharged into rivers [10]. Therefore, in the case of serious organic pollution, surface waters consume a large amount of dissolved oxygen. The negative correlation between OCP concentrations and DO in the Shanghai surface waters indicates that OCPs discharged into the rivers would affect the surface water quality. ORP reflects the redox potential of the surface water. From Fig. $4 d$, the surface waters of Shanghai show strong oxidative properties, which may be related to the high DO concentration in water. The higher ORP of water could make organic pollutants easier to be oxidatively decomposed, thus there was a negative correlation between them. $\mathrm{EC}$ is an indicator that reflects the concentration of salt in the surface water. At a certain temperature, $\mathrm{EC}$ is proportional to the salinity of water [21]. Studies have shown that higher salinity waters are more unfavorable to the dissolution of organic pollutants, which may be an important reason for the negative correlation between EC and OCP concentrations in the surface waters of Shanghai [22]. The $\mathrm{pH}$ of rainwater in Shanghai is mostly smaller than 7 , and the residual OCPs in farmland would enter rivers along with the surface runoff during rainfall. A large amount of surface runoff input led to the decrease of surface water $\mathrm{pH}$ and the increase of $\mathrm{OCP}$ accumulation in some areas.

Table A.4 shows the RDA ranked results between 26 OCPs and the suite of physio-chemical factors (T, TSS, DO, $\mathrm{EC}, \mathrm{pH}$, and ORP) in the surface waters of Shanghai. The eigenvalue of axis 1 is 0.6329 , and that of axis 2 is 0.0172 . These two ranking axes explained $65.01 \%$ of the differences in the distribution of OCPs and $98.43 \%$ of the relationship between differences between the distribution of OCPs and the physio-chemical factors. The pseudo-canonical correlation coefficient of OCPs and physio-chemical factors in axis 1 was 0.8983 , while the correlation coefficient in axis 2 was 0.4665 . The results of the RDA show that axis 1 could well reflect the relationship between the distribution difference of OCPs and physio-chemical factors, which had an important impact on the distribution of OCPs in the surface waters of Shanghai.

As shown in Fig. 4e, OCP individuals in the sampled surface waters had the highest correlation with axis 1, while four of the six physio-chemical factors had the highest correlation with axis 1 , namely DO, EC, pH, and ORP. These four physio-chemical factors had an obvious negative correlation with the OCP individuals (Fig. 4e), which is consistent with the conclusion of Fig. 4a-d. Due to the sampling time being concentrated in winter, the fluctuation of water temperature $\left(6.2-11.1^{\circ} \mathrm{C}\right)$ was not significant. Therefore, no obvious correlation between temperature and OCPs was observed. The correlation between TSS and OCPS was also insignificant, although TSS may affect the OCP concentrations in sediments and suspended particulate matter.

\subsection{Source apportionment of OCPs}

\subsection{1 $\mathrm{HCHs}$, HCB and DDTs}

Compositional differences between $\mathrm{HCH}$ isomers or DDT congeners in surface water environments could provide abundant and useful information for identifying different pollution sources and their environmental chemical behavior [20]. $\mathrm{HCHs}$ in the environment are mainly composed of four isomers, namely $\mathrm{a}-\mathrm{HCH}, \beta-\mathrm{HCH}, \gamma-\mathrm{HCH}$, and $\delta-\mathrm{HCH}$ [1]. Reportedly, a ratio of $\mathrm{a}-\mathrm{HCH} / \gamma-\mathrm{HCH}<1$ indicates that there has been an input of lindane, and a ratio between 1 and 3 indicates the input of industrial $\mathrm{HCHs}$, whereas a ratio $>3$ may indicates that $\mathrm{HCHs}$ comes from mixed sources of lindane and industrial $\mathrm{HCHs}$ [23]. In this study, in the samples with $\mathrm{a}-\mathrm{HCH}$ and $\mathrm{\gamma}-\mathrm{HCH}$ detected $(n=22)$, there were 10 sites whose ratios range from 1 to 3 , indicating an input of industrial HCHs (Fig. 5a). At 12 sampling sites the ratios of $\mathrm{a}-\mathrm{HCH} / \mathrm{\gamma}-\mathrm{HCH}>3$, thus indicating the mixed source of lindane and industrial $\mathrm{HCHs}$ (Fig. 5a). In addition, the ratio of $\mathrm{a}-\mathrm{HCH} / \mathrm{Y}-\mathrm{HCH}$ can be $>7$ 

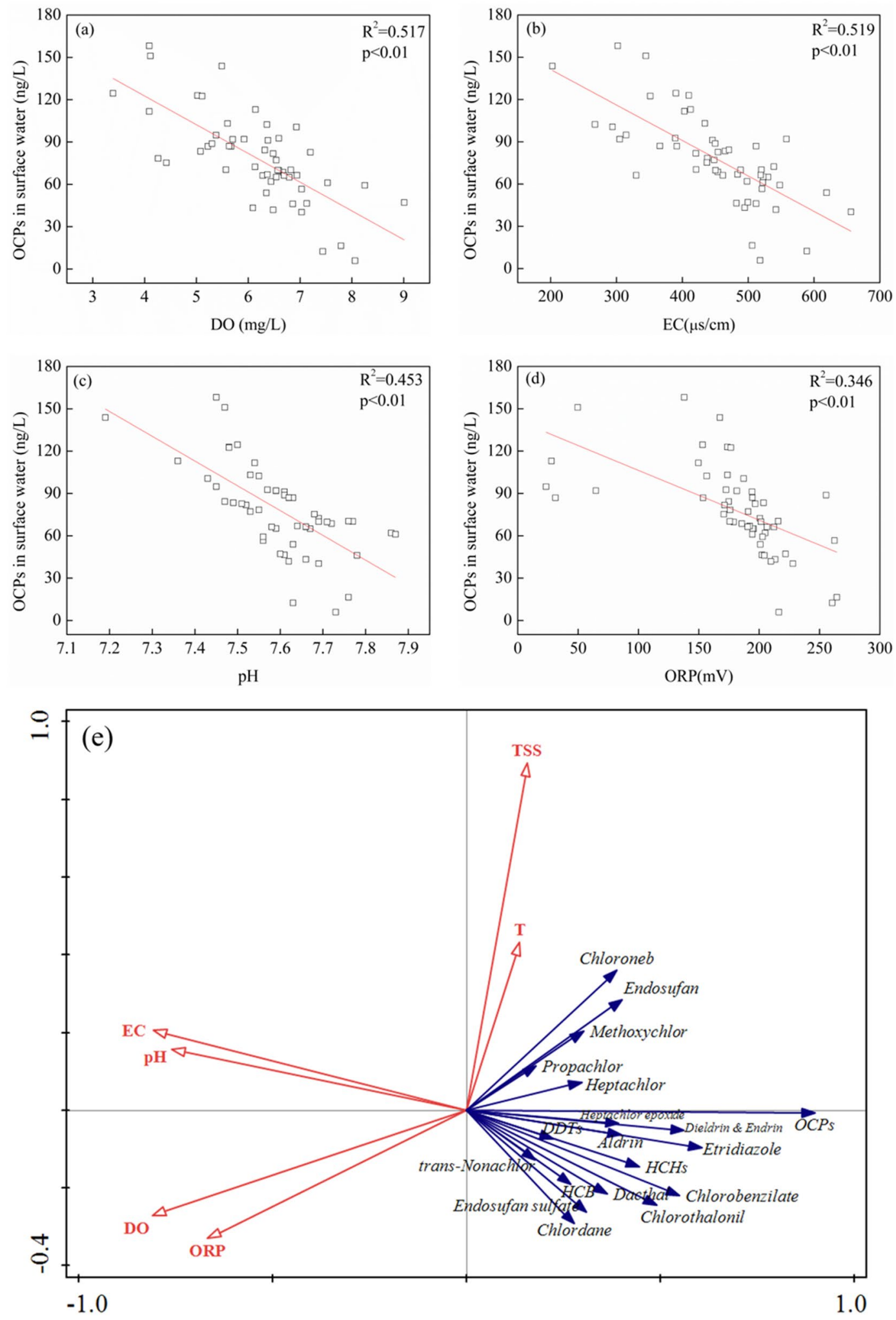

Fig. 4 Correlations between OCP concentrations and physiochemical factors in the surface water of Shanghai. $\mathrm{HCH}$ contained $\mathrm{a}-\mathrm{HCH}, \beta-\mathrm{HCH}, \mathrm{\gamma}-\mathrm{HCH}, \delta-\mathrm{HCH}$; Chlordane contained trans-chlordane and cis-chlordane; Endosufan contained Endosufan I and
Endosufan II; DDTs contained p, $\mathrm{p}^{\prime}-\mathrm{DDE}, \mathrm{p}, \mathrm{p}^{\prime}-\mathrm{DDD}$ and $\mathrm{p}, \mathrm{p}^{\prime}-\mathrm{DDT} . T$ temperature, TSS total suspended solids, EC electrical conductivity, $D O$ dissolved oxygen, ORP oxidation-reduction potential 

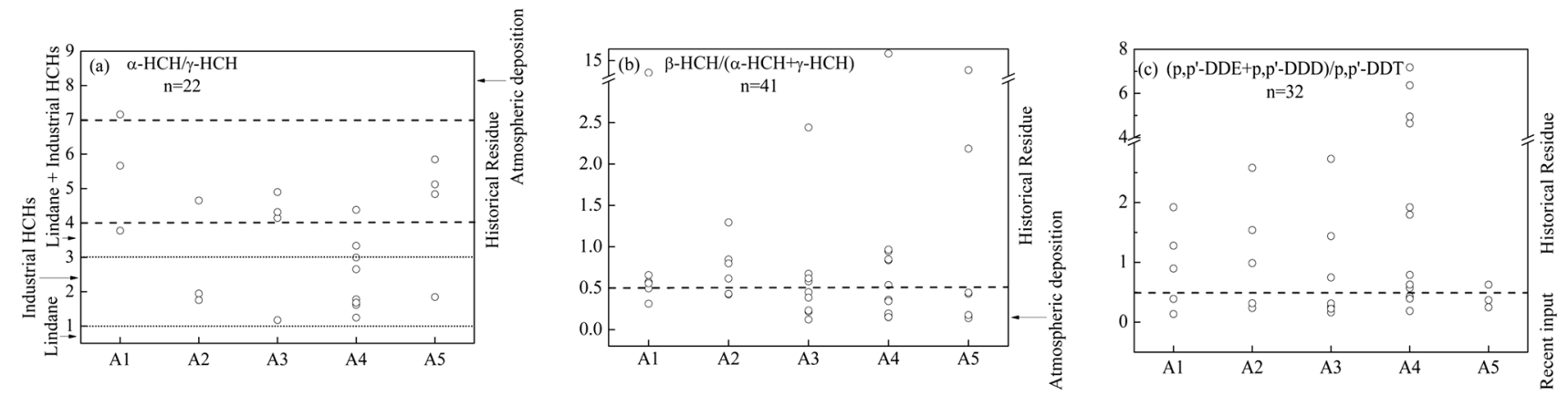

Fig. 5 Isomer ratios of OCPs in surface water of Shanghai: A1, suburban towns; A2, island areas; A3, industrial areas; $A 4$, agricultural areas; $\mathrm{A} 5$, inner city; $\mathrm{n}$ means the number of samples with a-HCH and $\mathrm{\gamma}-\mathrm{HCH}$ detected

under photochemical transformation of $\mathrm{\gamma}-\mathrm{HCH}$ into $\mathrm{a}-\mathrm{HCH}$ in the atmosphere during long range transport [24], which can further indicate $\mathrm{HCHs}$ originating from atmospheric deposition [23]. If the ratio is between 4 and $7, \mathrm{HCHs}$ in the environment may be mainly from historical residues [23]. In this study, 9 sampling sites had a ratio ranging from 4 to 7 , thus indicating historical residues. Only one site located in a suburban town (P42) had a ratio $>7$, which indicates that atmospheric deposition may be one of the main sources of $\mathrm{HCHs}$ in the surface water of this area (Fig. $5 \mathrm{a}$ ).

Compared with other isomers, $\beta-\mathrm{HCH}$ is the most stable and resistant to microbial degradation [25]. Therefore, $\beta-\mathrm{HCH} /(\mathrm{a}-\mathrm{HCH}+\gamma-\mathrm{HCH})$ can also indicate whether $\mathrm{HCH}$ in surface water come from historical residues $(>0.5)$, or from atmospheric deposition $(<0.5)$ [23]. Among the samples with $\beta-\mathrm{HCH}$ and $(\mathrm{a}-\mathrm{HCH}+\gamma-\mathrm{HCH})$ detected $(n=41)$, there were 21 sites whose ratios $>0.5$, thus indicating historical residues (Fig. 5b). At 20 sampling sites, ratios of $\beta-\mathrm{HCH} /$ $(a-H C H+\gamma-H C H)$ were $<0.5$, indicating atmospheric deposition (Fig. 5b). Overall, the contribution of historic residual $\mathrm{HCH}$ in Shanghai's surface waters was not significantly different from that of atmospheric deposition. From the perspective of different intensive land-use types, $\mathrm{HCHs}$ in more than half of the sampling sites in the inner city and industrial areas were derived from atmospheric deposition, whereas agricultural areas, island areas, and suburban towns were dominated by historical residual $\mathrm{HCHs}$ (Fig. 5b).

HCB has not been directly used as a pesticide in China, but it is a type of degradation product of many pesticides containing chlorine such as atrazine, pentachlorophenol, industrial $\mathrm{HCH}$ and lindane [26]. The correlation analysis between $\mathrm{HCB}$ and $\mathrm{HCHs}(\mathrm{a}-\mathrm{HCH}, \beta-\mathrm{HCH}, \gamma-\mathrm{HCH}$, and $\delta-\mathrm{HCH}$ ) was conducted, and the concentrations of $\mathrm{HCB}$ had a significant positive correlation with that of $\beta-\mathrm{HCH}$ with a Pearson correlation coefficient of $0.301(p<0.05)$. It indicated that a part of HCB in surface waters of Shanghai was likely from the degradation of $\mathrm{HCHs}$, and this conclusion is consistent with that of the previous studies conducted by Wu et al. [26] and Wang et al. [27].

DDE and DDD are products of DDT decomposition under aerobic and anaerobic conditions, respectively [1]. Therefore, the ratio of $\left(p, p^{\prime}-D D E+p, p^{\prime}-D D D\right) / p, p^{\prime}-D D T$ can reflect the input and degradation of DDT [1]. Among the 32 sampling sites with DDTs detected, 19 sites had ratios $>0.5$, thus indicating historical residual source of DDTs, whereas $13 \mathrm{had}$ ratios $<0.5$, thus indicating a recent input source (Fig. 5c). Studies have shown that DDT pollution caused by dicofol has been very significant in China [28]. Dicofol is one of the major acaricides in southern China because of the higher temperature, which is more suitable for mite survival and reproduction [28]. The southeastern coastal provinces of China (e.g., Shanghai, Fujian, and Jiangsu) have become the main areas using dicofol [29]. Research undertaken in the area of Taihu Lake, located in Jiangsu Province, also showed similar conclusions [28]. More attention should be paid to the production and use of dicofol and the corresponding environmental problems. Another important source of DDTs in China was antifouling paint that was used for fishing ships. Research showed that the use of antifouling paint, mainly for small and mediumsized ships, could result in the release of 150-300 million metric tons of DDTs to the environment every year [30]. There are a large number of ships sailing every day in the urbanized river network of Shanghai, leading to continuous input of DDTs [31].

\subsubsection{Heptachlors and aldrins}

Heptachlor is a type of OCP used not only against termites and other soil insects, but also in controlling malaria mosquitoes [26]. One of the most stable breakdown product of heptachlor is heptachlor epoxide, so it can be assessed together with heptachlor. Among the 50 sampling points with heptachlor or heptachlor epoxide detected, the concentrations of heptachlor epoxide in $66.0 \%$ surface water 
samples were higher than that of heptachlor, indicating that the main sources of heptachlor in the surface waters were the historical residues, although accompanied with some fresh input.

Aldrin has been used to kill soil pests and also protect the wooden structures against termites, and it is readily metabolized to dieldrin [26]. In this study, aldrin and dieldrin were detected in 50 sampling points. There were 27 (54.0\%) surface water samples with a higher concentration of aldrin than that of diedrin, giving priority to recent input sources, while the opposite was true for the other 23 $(46.0 \%)$ samples, indicating there may be some historical residues.

\subsubsection{APCS-MLR results for OCPs in surface waters}

APCS can be used to classify and identify the total variability of the principal components (PC) of OCPs with a minimum of factors [15]. An estimation of the principal components of OCPs can be attached to each factor by accurately evaluating the factor loadings. The purpose of the MLR is to further determine the contribution rate and contribution amounts of different principal components of OCPs based on PC identification [15]. In this study, six principal components of OCPs were identified (Table A.5). PC one was dominated by both dacthal and chlordane, and accounts for $18.87 \%$ of total variance. PC two was represented by heptachlor epoxide, and accounts for $13.89 \%$ of the total variance. PC three was dominated by endosufan and methoxychlor, and explains $9.68 \%$ of the total variance. PC four was represented by propachlor, and explains $9.49 \%$ of the total variance. PC five included heptachlor and DDTs, and explains $9.17 \%$ of the total variance. PC six was represented by $\mathrm{HCHs}$, and explains $9.00 \%$ of the total variance (Table A.5). The six principal components of OCPs identified by APCS account for $70.11 \%$ of the total variance, and involve nine of the most important OCPs in Shanghai's surface waters.

In general, the contribution rates of OCPs principal components in the surface waters of Shanghai were $28.35 \%$, $19.77 \%, 17.67 \%, 16.28 \%, 15.58 \%$, and $2.35 \%$ for heptachlor epoxide, $\mathrm{HCHs}$, endosufan and methoxychlor, propachlor, heptachlor and DDTs, dacthal and chlordane, respectively (Table A.5). As is mentioned above, heptachlor epoxide is one of the breakdown product of historical residual heptachlor. $\mathrm{HCHs}$ also mainly come from historical residues, and some are from atmospheric deposition (Fig. 5a, b). Endosufan includes two isomers, endosufan I and endosufan II. Due to the threat that it poses to the environment, endosufan has been incorporated into the Stockholm Convention and forbidden for manufacture or use in many areas [32]. China still reserves exemption for endosufan production until now, which may be responsible for the relatively high contribution rate in Shanghai's surface waters [33]. Methoxychlor is a good alternative to DDTs, which can be used to control ectoparasites and hygienic pests in livestock, and has a wide range of uses [34]. Propachlor is a low-toxicity herbicide that can be used not only in crop fields but also in orchard and nursery weeding [35]. Thus, it can enter urban rivers from farmland through surface runoff as a result of its wide production and uses. DDTs is a type of pesticide that has also been incorporated into the Stockholm Convention and is prohibited from being produced and used [36]. It can be inferred that concentrations detected in our study were mainly from historical residues. The contribution rate of dacthal and chlordane (containing trans-chlordane and cis-chlordane) was very low, indicating infrequent use in agricultural activities.

The differences of contribution rates and contribution amounts in diverse intensive land-use areas were slight (Fig. 6a, b), and the rankings were as follows. Suburban towns: heptachlor epoxide $>$ propachlor $>$ heptachlor and DDTs $>\mathrm{HCH}$ s $>$ endosufan and methoxychlor $>$ dacthal and chlordane (Fig. 6a, b). Island areas: heptachlor epoxide $>\mathrm{HCHs}>$ heptachlor and DDTs $>$ propachlor $>$ endosufan and methoxychlor $>$ dacthal and chlordane (Fig. 6a, b). Industrial areas: heptachlor epoxide $>$ endosufan and methoxychlor $>\mathrm{HCHs}>$ propachlor $>$ heptachlor and DDTs $>$ dacthal and chlordane (Fig. 6a, b). Agricultural areas: heptachlor epoxide $>\mathrm{HCH}>$ endosufan and methoxychlor $>$ heptachlor and DDTs $>$ propachlor $>$ dacthal and chlordane (Fig. 6a, b). Inner city: heptachlor epoxide $>$ propachlor $>$ endosufan and methoxychlor $>\mathrm{HCHs}>$ heptachlor and DDTs $>$ dacthal and chlordane (Fig. 6a, b). POPs can be transported between different regions due to their ease of volatilization, migration, and deposition, which has been termed the Grasshopper Effect [4]. In addition, the surface waters in Shanghai are interlaced together and present characteristics that are typical of an alluvial plain river network [10]. Due to the generally good hydrodynamic conditions in the surface waters of Shanghai, the water flow rate is relatively fast. As a result, the migration and transformation of POPs between diverse intensive land-use types is relatively easy, and regional differences of OCPs are weakened to some extent, but still show slight regional characteristics.

\section{Conclusions}

The concentrations of OCPs in the surface waters of Shanghai ranged from 5.90 to $158.16 \mathrm{ng} / \mathrm{L}$. Chloroneb, chlorobenzilate, and chlorothalonil were the major pollutants. The OCP concentrations were generally low, with only a few relatively high concentration sites in the northern and southern regions of Shanghai. The fluctuation of 


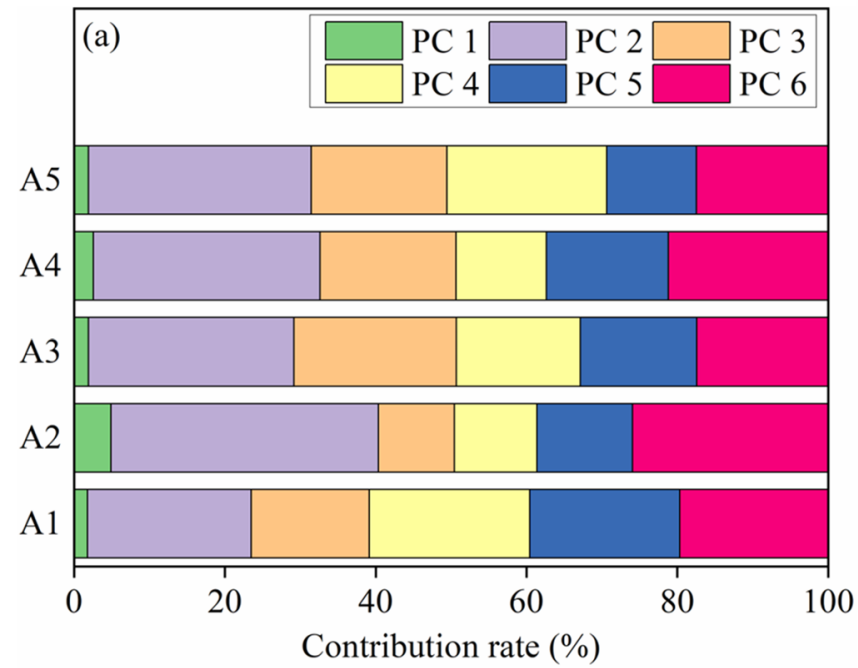

Fig. 6 Contribution rate and contribution amount of 26 OCPs by APCS-MLR in surface water of Shanghai: A1, suburban towns; $A 2$, island areas; $A 3$, industrial areas; $A 4$, agricultural areas; $A 5$, inner

OCP concentrations among different intensive land-use types was relatively insignificant $(p>0.05)$. The OCP concentrations showed a significant negative correlation with DO, EC, $\mathrm{pH}$, and ORP $(p<0.01)$, which had an important impact on the distribution of OCPs. The contribution of historic residual $\mathrm{HCHs}$ was not found to be significantly different from that of atmospheric deposition, and a part of HCB was likely from the degradation of HCHs. DDTs and heptachlors were mainly from historical residues. However, the recent input and historical residues of aldrins were both noticeable. Six principal components (PC) of OCPs were identified through APCS-MLR, and the contribution rate and contribution amount of each PC were ranked. Regional differences in OCP principal components may be weakened to some extent as a result of the Grasshopper Effect and also due to the favorable hydrodynamic conditions of the Shanghai river network.

Authors' contributions CC and LM designed the study. CC and TL were involved in the sampling and experiments. CC and WZ were involved in the data analysis and manuscript writing. LM, SC, and KZ contributed to correction of the manuscript. All authors read and approved the final manuscript.

Funding This work was financially supported by Most Key Program of China (2017YFC0505705, 2017ZX07206-003) and the Natural Science Foundation of China (No. 21377098).

Availability of data and materials The datasets used and analyzed during the current study are available from the corresponding author on reasonable request.

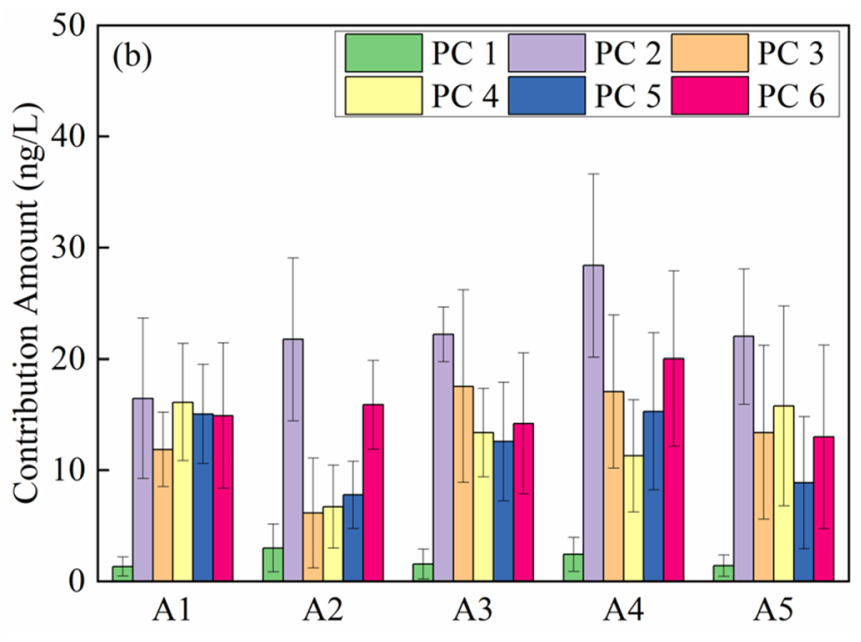

city. PC 1 is dacthal and chlordane; PC 2 is heptachlor epoxide; PC 3 is endosufan and methoxychlor; PC 4 is propachlor; PC 5 is heptachlor and DDTs; PC 6 is $\mathrm{HCHs}$

\section{Compliance with ethical standards}

Conflict of interest The authors declare that there are no conflicts of interest.

Code availability Not applicable.

\section{Appendix A: Supplementary material}

Supplementary material associated with this article can be found in Appendix A.

\section{References}

1. Zhi H, Zhao Z, Zhang L (2015) The fate of polycyclic aromatic hydrocarbons (PAHs) and organochlorine pesticides (OCPs) in water from Poyang Lake, the largest freshwater lake in China. Chemosphere 119:1134-1140. https://doi.org/10.1016/j.chemo sphere.2014.09.054

2. Meng J, Hong S, Wang T, Li Q, Yoon SJ, Lu Y, Giesy JP, Khim JS (2017) Traditional and new POPs in environments along the Bohai and Yellow Seas: an overview of China and South Korea. Chemosphere 169:503-515. https://doi.org/10.1016/j.chemo sphere.2016.11.108

3. Zhang L, Li X, Yu J, Yao X (2018) Toward cleaner production: what drives farmers to adopt eco-friendly agricultural production? J Clean Prod 184:550-558. https://doi.org/10.1016/j.jclep ro.2018.02.272

4. Pouokam GB, Lemnyuy Album W, Ndikontar AS, Sidatt MEH (2017) A pilot study in Cameroon to understand safe uses of pesticides in agriculture, risk factors for farmers' exposure and management of accidental cases. Toxics 5(4):30-44. https://doi. org/10.3390/toxics5040030 
5. Harmouche-Karaki M, Matta J, Helou K, Mahfouz Y, FakhourySayegh N, Narbonne JF (2018) Serum concentrations of selected organochlorine pesticides in a Lebanese population and their associations to sociodemographic, anthropometric and dietary factors: ENASB study. Environ Sci Pollut Res 25(15):14350-14360. https://doi.org/10.1007/s11356-017-9427-1

6. Han D, Currell MJ (2017) Persistent organic pollutants in China's surface water systems. Sci Total Environ 580:602-625. https://doi. org/10.1016/j.scitotenv.2016.12.007

7. Bai Y, Ruan X, Hoek JPVD (2018) Residues of organochlorine pesticides (OCPs) in aquatic environment and risk assessment along Shaying River, China. Environ Geochem Health 40(6):2525-2538. https://doi.org/10.1007/s10653-018-0117-9

8. Wang H, Ma Y, Li G, Jin J, He C, Li Q, Wang Y (2017) Levels and distribution of organochlorine pesticides in surface water and sediments from the Yellow River Basin. Environ Sci Technol 40(11):160166. https://doi.org/10.3969/j.issn.1003-6504.2017.11.026

9. Yang Q, Mai B, Fu J, Sheng G, Hu X (2005) Studies on organochlorine pesticides (OCPs) in waters of Pearl River artery water. China Environ Sci 25:47-51

10. Bi C, Wang X, Jia J, Chen Z (2018) Spatial variation and sources of polycyclic aromatic hydrocarbons influenced by intensive land use in an urbanized river network of East China. Sci Total Environ 627:671-680. https://doi.org/10.1016/j.scitotenv.2018.01.272

11. Liu S, Liu X, Liu M, Yang B, Cheng L, Li Y, Qadeer A (2016) Levels, sources and risk assessment of PAHs in multi-phases from urbanized river network system in Shanghai. Environ Pollut 219:555567. https://doi.org/10.1016/j.envpol.2016.06.010

12. Shanghai Municipal People's Government (SMPG) (2010) The encyclopedia of Shanghai. Shanghai Science and Technology Press, Shanghai

13. Shanghai Municipal Statistics Bureau (SMSB) (2018) Shanghai statistical year book. China Statistics Press, Beijing

14. United States Environmental Protection Agency (USEPA) (2012) Determination of semivolatile organic chemicals in drinking water by solid phase extraction and capillary column gas chromatography/mass spectrometry (GC/MS). USEPA, Washington

15. Gholizadeh MH, Melesse AM, Reddi L (2016) Water quality assessment and apportionment of pollution sources using APCS-MLR and PMF receptor modeling techniques in three major rivers of South Florida. Sci Total Environ 566-567:1552-1567. https://doi. org/10.1016/j.scitotenv.2016.06.046

16. Chen C, Zou W, Cui G, Tian J, Wang Y, Ma L (2020) Ecological risk assessment of current-use pesticides in an aquatic system of Shanghai, China. Chemosphere 257:127222-127231. https://doi. org/10.1016/j.chemosphere.2020.127222

17. Zarghami SA, Gunawan I, Schultmann F (2018) Integrating entropy theory and cospanning tree technique for redundancy analysis of water distribution networks. Reliab Eng Syst Saf 176:102-112. https://doi.org/10.1016/j.ress.2018.04.003

18. Chen C, Zou W, Chen S, Zhang K, Ma L (2020) Ecological and health risk assessment of organochlorine pesticides in an urbanized river network of Shanghai, China. Environ Sci Eur 32(1):42-55. https:// doi.org/10.1186/s12302-020-00322-9

19. Elfman L, Tooke NE, Patring JDM (2011) Detection of pesticides used in rice cultivation in streams on the island of Leyte in the Philippines. Agric Water Manag 101(1):81-87. https://doi. org/10.1016/j.agwat.2011.09.005

20. Wang Y, Zhang S, Cui W, Meng X, Tang X (2018) Polycyclic aromatic hydrocarbons and organochlorine pesticides in surface water from the Yongding River basin, China: seasonal distribution, source apportionment, and potential risk assessment. Sci Total Environ 618:419-429. https://doi.org/10.1016/j.scito tenv.2017.11.066

21. Robbins CW, Meyer WS (1990) Calculating $\mathrm{pH}$ from EC and SAR values in salinity models and SAR from soil and bore water $\mathrm{pH}$ and
EC data. Soil Res 28(6):1001-1011. https://doi.org/10.1071/sr990 1001

22. Grundl G, Müller M, Touraud D, Kunz W (2017) Salting-out and salting-in effects of organic compounds and applications of the salting-out effect of Pentasodium phytate in different extraction processes. J Mol Liq 236:368-375. https://doi.org/10.1016/j.molli q.2017.03.091

23. Chakraborty P, Zhang G, Li J, Sivakumar A, Jones KC (2015) Occurrence and sources of selected organochlorine pesticides in the soil of seven major Indian cities: assessment of air-soil exchange. Environ Pollut 204:74-80. https://doi.org/10.1016/j.envpo I.2015.04.006

24. Willett KL, Ulrich EM, Hites RA (1998) Differential toxicity and environmental fates of hexachlorocyclohexane isomers. Environ Sci Technol 32(15):2197-2207. https://doi.org/10.1021/es9708530

25. Li YF, Scholtz MT, Heyst BJV (2003) Global gridded emission inventories of $\beta$-hexachlorocyclohexane. Environ Sci Technol 37(16):3493-3498. https://doi.org/10.1021/es034157d

26. Wu C, Luo Y, Gui T, Huang Y (2014) Concentrations and potential health hazards of organochlorine pesticides in shallow groundwater of Taihu Lake region, China. Sci Total Environ 470-471:10471055. https://doi.org/10.1016/j.scitotenv.2013.10.056

27. Wang F, Jiang X, Bian YR, Yao FX, Gao HJ, Yu GF, Munch JC, Schroll $\mathrm{R}$ (2007) Organochlorine pesticides in soils under different land usage in the Taihu Lake region, China. J Environ Sci (China) 19:584-590

28. Qiu X, Zhu T, Li J, Pan H, Li Q, Miao G, Gong J (2004) Organochlorine pesticides in the air around the Taihu Lake, China. Environ Sci Technol 38(5):1368-1374. https://doi.org/10.1021/es035052d

29. Qiu X, Zhu T, Yao B, Hu J, Hu S (2005) Contribution of dicofol to the current DDT pollution in China. Environ Sci Technol 39(12):43854390. https://doi.org/10.1021/es050342a

30. Lin T, Hu Z, Zhang G, Li X, Xu W, Tang J, Li J (2009) Levels and mass burden of DDTs in sediments from fishing harbors: the importance of DDT-containing antifouling paint to the coastal environment of China. Environ Sci Technol 43(21):8033-8038. https://doi. org/10.1021/es901827b

31. Rony AH, Kitada M, Dalaklis D, Ölçer Al, Ballini F (2019) Exploring the new policy framework of environmental performance management for shipping: a pilot study. WMU J Marit Affairs 18(1):124. https://doi.org/10.1007/s13437-019-00165-z

32. Jia H, Li YF, Wang D, Cai D, Yang M, Ma J, Hu J (2009) Endosulfan in China 1-gridded usage inventories. Environ Sci Pollut Res Int 16(3):295-301. https://doi.org/10.1007/s11356-008-0042-z

33. Jia H, Sun Y, Li YF, Tian C, Wang D, Yang M, Ding Y, Ma J (2009) Endosulfan in China 2-emissions and residues. Environ Sci Pollut Res Int 16(3):302-311. https://doi.org/10.1007/s11356-009-0125-5

34. Chen M, Chen L, Huang P (2015) Assessment, composition and possible source of organochlorine pesticides in surface soils from Ürümqi, China. Pedosphere 25(6):888-900. https://doi. org/10.1016/s1002-0160(15)30069-2

35. Zheng W, Yates SR, Papiernik SK, Guo M (2004) Transformation of herbicide propachlor by an agrochemical thiourea. Environ Sci Technol 38:6855-6860. https://doi.org/10.1021/es049384+

36. Yang Y, Liu M, Yun X, Ge J, Wang J (2017) Profiles and risk assessment of organochlorine pesticides in Three Gorges Reservoir. China. Clean Soil Air Water 45(2):1600823-1600829. https://doi. org/10.1002/clen.201600823

Publisher's Note Springer Nature remains neutral with regard to jurisdictional claims in published maps and institutional affiliations. 